\title{
DA ATUALIDADE À ONTOLOGIA CRÍTICA: O MOVIMENTO PENDULAR DA MODERNIDADE ENTRE MICHEL FOUCAULT E IMMANUEL KANT
}

\section{Guilherme Roman Borges}

Mestrando em Filosofia do Direito na USP, Mestrando em Sociologia do Direito na UFPR.

SUMÁRIO: 1 A Presença de Kant na Obra de Foucault; 2 A Interpretação da Modernidade: a Atualidade à Ontologia Crítica; Referências Bibliográficas.

\section{A PRESENÇA DE KANT NA OBRA DE FOUCAULT}

IMMANUEL KANT, filósofo do séc. XVIII e início do séc. XIX, tem uma importância significativa na obra foucaultiana, pois, como é notório, ao expor FOUCAULT sua tese sobre a história da loucura, apresentara uma interpretação sobre a Antropologia de Kant, manuscrito esse que, embora contendo significativas 130 grandes páginas, defendido igualmente no dia 20 de maio de 1961, perante JEAN HYPPOLITE (que aceitara ser orientador deste ensaio, ao contrário da tese principal) e MAURICE DE CANDILLAC, jamais seria publicado, segundo a vontade do próprio FOUCAULT.

É nessa apresentação que FOUCAULT traça sua influência sobre a teoria kantiana, procurando encontrar na "antropologia" uma perspectiva fundada numa análise estrutural e numa análise genética. Busca fazer uma "arqueologia do texto kantiano", isto é, fazer uma escavação da geologia kantiana, e a posição correta do referido texto na epistemologia crítica de IMMANUEL KANT. ${ }^{1}$ Todavia, como a este ensaio não foi dado publicidade, é preciso investigar a importância da base kantiana em outros textos publicados por FOUCAULT, que são capazes de trazer uma lúcida noção da importância do filósofo alemão para as suas considerações, posto que, como dissera em julho de 1966, "somos todos neokantianos". ${ }^{2}$

Inicialmente, é necessário observar que, após a publicação de Les Mots et les Choses, a primeira vez que FOUCAULT faz referência ao pensamento de KANT foi em abril de 1979, por ocasião de suas reflexões sobre as críticas que sofrera ao ir ao Irã, como se observa na Revista Le Nouvel Observateur. Nesta matéria, FOUCAULT faz suas primeiras alusões à clássica pergunta kantiana Was ist Aufklärung?, antes mesmo de publicar Qu'est-ce que les lumières?, quando esmiuça o tema do kantismo em sua 
obra. ${ }^{3}$ Convém alertar, como faz o ilustre Professor SÉRGIO ADORNO, que a FOUCAULT interessava muito mais as obras políticas do que as robustas obras kantianas, pois representavam a possibilidade de um KANT marginal. ${ }^{4}$

Todavia, para melhor estudar o assunto, convém investigar dois textos principais, sem embargo as inúmeras entrevistas em que FOUCAULT se refere ao pensamento kantiano, ou mesmo em Les Mots et les Choses, ainda que de maneira ambígua, segundo BÉATRICE HAN, ${ }^{5}$ especialmente: Qu'est-ce que les lumières? ${ }^{6}$ publicado na Revista Magazine Littéraire, em abril de 1994, que foi logo esgotado e, posteriormente, reeditado na mesma revista no ano de 1993 (de fato se trata de um curso proferido por FOUCAULT no dia 5 de janeiro de 1983 no Collège de France), e Qu'est-ce que la critique? Critique et Aufklärung, ${ }^{7}$ publicado no Bulletin de la Société Française de Philosophie, no segundo trimestre de 1990, sem que FOUCAULT fizesse a sua revisão.

É importante também ressaltar que FOUCAULT fez parte de um importante debate em torno da concepção kantiana em março de 1983, quando este intelectual e Jürgen Habermas se conheceram, fizeram parte de um seminário para discutir o bicentenário da aparição do clássico artigo Was ist Aufklärung?, escrito por IMMANUEL KANT, e publicado em 1784 no jornal Berlinische Monatsschrift, tal como dispõe Habermas, num artigo intitulado Une flèche dans le coeur du temps présent, publicado na renomada edição da Critique de agosto/setembro de $1986 .{ }^{8}$ Dessa maneira, a presença das reflexões kantianas na obra de MICHEL FOUCAULT se faz evidente; todavia, essa relação não é simplesmente amistosa, posto que inúmeras diferenças o levam a se distanciar da teoria de KANT. É nesse sentido que as linhas que se seguem procuram enfrentar o problema das proximidades, através da questão da atualidade, e dos distanciamentos, pelo tema da ontologia crítica, entre a teoria kantiana e a do intelectual francês.

3 FOUCAULT, Michel. Pour une morale de l'inconfort. Dits et Écrits. Daniel Defert et François Ewald (orgs.). Paris: Gallimard, v. 3, 1994, p. 783-787.

4 ADORNO, Sérgio. Dor e sofrimento: presenças ou ausências na obra de Foucault? In: Cadernos da Faculdade de Filosofia e Ciência de Marília "Michel Foucault: histórias e destinos de um pensamento". Fávia Biroli e Marcos César Alvarez (orgs.). Marília: Ed. da Unesp, v. 9, n. 1, p. 26, 2000.

5 HAN, Béatrice. L'ontologie manquée de Michel Foucault: entre l'historique et le transcendantal. Grenoble: Millon, 1998, p. 31-37.

6 FOUCAULT, Michel. Qu'est-ce que les lumières? Magazine Littéraire, Paris, n. 09, avril, p. 61-73, 1993. [Trad. al. Was ist aufklärung? Ethos der Moderne: Foucaults Kritik der Aufklärung. Eva Erdmann, Rainer Forst e Axel Honneth (orgs.). Frankfurt: Campus Verlag, 1990, p. 35-54].

7 FOUCAULT, Michel. Qu'est-ce que la critique? Critique et Aufklärung. Bulletin de la Société Française de Philosophie. Paris, abr./jun. 1990, n. 2, p. 35-63. [Trad. br. O que é a crítica? Crítica e Aufklärung. Trad. de Antônio C. Galdino. In: Cadernos da Faculdade de Filosofia e Ciência de Marília "Michel Foucault: histórias e destinos de um pensamento". Fávia Biroli e Marcos César Alvarez (orgs.). Marília: Ed. da Unesp, v. 9, n. 1, p. 169-189, 2000]

8 HABERMAS, Jürgen. Une flèche dans le coeur du temps présent. Critique: Revue générale des publications françaises et étrangère, Paris, n. 471-472, p. 794, août/septembre, 1986. "Je n'ai fait la connaissance de Foucault qu'en mars 83." [Trad. do autor. "Eu só conheci Foucault em março de 1983”] 


\section{A INTERPRETAÇÃO DA MODERNIDADE: DA ATUALIDADE À ONTOLOGIA CRÍTICA}

A questão kantiana em FOUCAULT perpassa, antes de tudo, por um debate que convém ser aqui investigado, referente à posição das concepções foucaultianas, especialmente através de sua ontologia crítica em relação ao tema da modernidade. Antes de se ingressar propriamente nas semelhanças entre o pensamento de FOUCAULT e as considerações teóricas elaboradas pelas orientações kantianas, sobretudo no que tange ao tema da atualidade e da crítica da razão moderna, é necessário investigar a relação entre a teoria de FOUCAULT e a modernidade, isto é, seria FOUCAULT um filósofo moderno, ou um teórico pós-moderno, ou mesmo, tal afirmara HABERMAS (como se verá adiante), numa clássica palestra proferida no dia 11 de setembro de 1980, por ocasião da recepção do Prêmio Adorno da Cidade de Frankfurt, e publicado como artigo, intitulado La Modernité: Un Projet Inachevé, em outubro de 1981 na Revue Critique, um jeune conservateur [jovem conservador], de um anti-modernisme impitoyable? [antimodernismo impiedoso]. ${ }^{9}$ É nesse sentido que se faz indispensável investigar a posição de suas críticas.

Apesar de FOUCAULT estabelecer horizontes críticos em relação à razão moderna, a partir de seu método arqueológico na constituição dos saberes, pela implicação direta entre a relação saber e poder, isso não pode levar jamais ao entendimento de que o autor teria se afastado claramente das orientações da modernidade. Quando questiona os princípios da razão iluminista, e toda a sua capacidade de realizar os ideais do homem em busca de sua autonomia econômica, política, individual, intelectual, etc., abandonando evidentemente as filosofias do sujeito e a analítica da finitude não o torna pós-moderno, ou, como dissera HABERMAS, um "antimodernista impiedoso". Tal como ADORNO e HORKHEIMER, FOUCAULT estabelece uma atitude crítica em relação à modernidade de dentro de suas próprias estruturas, do ponto em que a razão moderna não foi capaz de atingir seus objetivos emancipatórios, isto é, na sua inabilidade para realizar os valores da universalidade, da autonomia e da individualidade liberta. A sua atitude crítica em relação à razão moderna não o afasta da modernidade, quer dizer, ao criticar a sua instrumentalidade não o distancia evidentemente da tradição deixada pela crítica moderna. Quando questiona a razão instrumental, e também autônoma, em suma, a razão unitária, na produção de um sujeito transcendental da metafísica clássica, quando se afasta das considerações de KANT, não o faz de maneira exterior, niilista, tal quisera JOSÉ GUILHERME MERQUIOR, ao afirmar que FOUCAULT acabava por "lançar farpas" à sua identidade intelectual e por jogar KANT contra KANT, já que seria impossível fazer uma ontologia do presente longe do saber científico, ${ }^{10}$ mas sim para permitir que uma crítica constante permanecesse ao presente.

9 HABERMAS, Jürgen. La modernité: un projet inachevé. Critique: Revue générale des publications françaises et étrangère. Paris, n. 413, p. 950-967, oct. 1981.

10 MERQUIOR, José Guilherme. Michel Foucault ou o niilismo de cátedra. Trad. Donaldson M. Garschagen. Rio de Janeiro: Nova Fronteira, 1985, p. 230-232. 
Nessa perspectiva, a crítica de suas estruturas, especialmente da razão e as formas de sujeição, dá a FOUCAULT necessariamente uma feição iluminista, posto que sua atitude crítica é própria do "esclarecimento", e não há como negar isso. Nesse sentido, defende BOAVENTURA DE SOUZA SANTOS: "A última grande tentativa de produzir uma teoria crítica moderna coube a FOUCAULT, tomando precisamente como alvo o conhecimento totalizante da modernidade, a ciência moderna. Ao contrário da opinião corrente, FOUCAULT é para mim um crítico moderno e não um crítico pós-moderno. Ele representa o clímax e, paradoxalmente, a derrocada da teoria crítica moderna. (...) O grande mérito de FOUCAULT foi ter mostrado as opacidades e os silêncios produzidos pela ciência moderna, conferindo credibilidade à busca de 'regimes da verdade' alternativos, outras formas de conhecer marginalizadas, suprimidas e desacreditadas pela ciência moderna". ${ }^{11}$

Essa questão da modernidade, que deve ser investigada mais detalhadamente, leva, portanto, aos dois pontos que aqui serão questionados para verificar a relação entre FOUCAULT e KANT: a) uma crítica da razão moderna, unitária, autônoma, universal, e instrumental, que os distancia; b) e uma ontologia do presente, que aproxima ambos intelectuais. Para tanto, em busca da defesa de um FOUCAULT moderno, convém investigar com mais afinco os textos supramencionados em que FOUCAULT se afirma enquanto na linha direta dos teóricos modernos, bem como o próprio texto kantiano utilizado por FOUCAULT, a fim de investigar sua atitude crítica.

a) Num primeiro aspecto, a diferença da crítica empreendida por FOUCAULT à razão kantiana, enquanto uma razão universal, é evidente, e não convém aqui ser detalhada, já que não se trata de exclusividade do intelectual francês. A partir do instante que FOUCAULT passa a investigar a noção de episteme e, portanto, de historicizar o conhecimento e a razão, destacando-lhes as condições de verdade nas suas particularidades, certamente se distancia de qualquer forma de ver a razão de maneira unitária, mas sim fragmentada, específica, particular e perspectiva.

b) Convém, todavia, demorar-se pelo ponto de encontro entre os dois autores, já que se está tentando buscar as bases do pensamento foucaultiano. O texto kantiano, que fora questionado por FOUCAULT, por ocasião do bicentenário de sua publicação, ao longo do curso de 1983 no Collège de France, é o artigo publicado por IMMANUEL KANT, no jornal Berlinische Monatsschrift, em 5 de dezembro de 1783, intitulado Beantwortung der Frage: Was ist Aufklärung? ${ }^{12}$

Esse texto leva à compreensão de duas questões primordiais que aqui precisam ser revisitadas: primeiro, que a filosofia kantiana, tal como FOUCAULT defenderá

11 SANTOS, Boaventura de Souza. A crítica da razão indolente: contra o desperdício da experiência. São Paulo: Cortez, 2000, p. 26-27.

12 KANT, Immanuel. Beantwortung der frage: was ist aufklärung? Schriften zur anthropologie geschichtsphilosophie, politik und pädagogik 1. Frankfurt: Suhrkamp, 1991, p. 53-61. 
posteriormente, ao assemelhar o seu projeto crítico, é certamente uma ontologia do presente, uma crítica da atualidade, do momento em que se vive; segundo, que é possível fazer uma crítica interna, quer dizer, é possível no próprio iluminismo encontrar a possibilidade de se fazer críticas à sua estrutura, sem que, com isso, possa-se desnaturalizar um pensamento como "moderno", quer dizer, o próprio KANT permitirá rescender de seu texto que os homens não devem jamais aceitarem num domínio externo, senão que devem estar em constante posicionamento crítico, já que é a maioridade de suas possibilidades, de sua autonomia e independência é que lhe permitem atingir seu "esclarecimento".

Dirigindo-se às bases de questionamento do pensamento foucaultiano, seria preciso reconhecer até que ponto teria realmente o texto elaborado por KANT um conteúdo exclusivamente filosófico, ou até que ponto poderia existir uma relação com o jornalismo e a afirmação política através de seus meios de comunicação. Esse texto trata, em breves palavras, da necessidade que os homens devem ter de se libertarem de seu estado de menoridade e passarem a um estado de autonomia, para que se tornem livres e esclarecidos. Inicia-se com a seguinte afirmação, que importa ser transcrita, dado seu caráter sintomático: "Esclarecimento é a saída do homem de sua menoridade, da qual ele próprio é culpado. A menoridade é a incapacidade de fazer uso de seu entendimento sem a direção de outro indivíduo". ${ }^{33}$ Essa passagem, por conseqüência, destaca três reflexões interdependentes que precisam ser investigadas: primeira, é a questão do "esclarecimento" [Aufklärung]; segunda, é questão da definição da "menoridade" [Unmündigkeit]; e, terceira, uma passagem intercorrente ao longo do texto, que lhe dá um sentido especial, que é de "culpa" [Shuld].

Consoante KANT, a menoridade dos homens se verifica na dependência que algumas pessoas têm de outros, isto é, grande parte dos homens, em razão, sobretudo, de sua preguiça e de sua covardia, causas essas supremas, que importam na referida culpa, verifica-se incapaz de servir a si mesmo sem a direção de outrem, e, aqui, KANT utiliza tipicamente a expressão latina sapere aude, para demonstrar que os homens devem ser capazes de tentar, de ousar, em suma, de se aventurarem no exercício de seu próprio entendimento, como forma de sair desse estado de menoridade para atingir a maioridade, o esclarecimento. Se de um lado a preguiça e a covardia representam a culpa dessa menoridade, que KANT refere-se ao menos quatro vezes em sete páginas, na necessidade de demonstrar que os homens estariam presos a esse estado de inacapacidade de fazer uso de seu próprio entendimento, de serem, portanto, esclarecidos, por conta própria, há também um outro lado, há outras causas que não atuam exclusivamente sobre os "menores", mas que atuam sobre os outros, que se pretendem ser os guias na busca individual pelo esclarecimento. Há causas externas que fazem também que uns se constituam como tutores [Vormündern] de outros, ou

13 KANT, Immanuel. Beantwortung der frage..., p. 53. "Aufklärung ist der Ausgang des Menschen aus seiner selbst verschuldeten Unmündigkeit. Unmündigkeit ist das Unvermögen, sich seines Verstandes ohne Leitung eines anderen zu bedienen". [Trad. do autor] 
seja, há causas que fazem com que alguns indivíduos submetam o pensamento individual ou de um povo mesmo ao seu poder tutelar. Entretanto, KANT não vai além nesse ponto, embora esboce a necessidade que alguns têm de fazer de outros rebanho, ensinando-lhes os perigos de andarem sozinhos, pois seu interesse é refletir a questão individual na incapacidade de atingir o esclarecimento.

Nessa linha, de maneira sintética, KANT se utiliza de uma oração reduzida de infinitivo para afirmar, até de maneira jocosa e simples, a sensação que experimentam aqueles que se encontram na dependência de outros: "É tão cômodo ser menor". ${ }^{14}$ Para os covardes e os preguiçosos há sempre um livro que faz as vezes do entendimento, há sempre um diretor espiritual (nesse tópico KANT se extende em seguida) que conduz a consciência individual; há sempre um médico que decide sobre a dieta do próprio indivíduo etc., o que conduz os indivíduos a não se esforçarem. Existindo sempre alguém para reger seus negócios e pensar por ele, o indivíduo tardará sempre em encontrar seu esclarecimento, em suma, sua independência: "Um homem sem dúvida pode, no que diz com a sua pessoa, e mesmo assim só por algum tempo, na parte que lhe incumbe, adiar o esclarecimento". ${ }^{15}$ O que decorre dessa interpretação que KANT estabelece inicialmente é que há um processo de naturalização da menoridade no indivíduo, de tal maneira que ele chega até a "criar amor por ela", tornando-se fato de sua própria natureza, e o impedindo de utilizar seu próprio entendimento. É através dos preceitos [Satzungen] e das fórmulas [Formeln], instrumentos mecânicos da razão, que induzem o indivíduo a permanecer nesse estado de menoridade. O público, em virtude de preceitos e fórmulas, também encontra resistência em atingir sua maioridade, e só o faz de maneira lenta e gradual, jamais de maneira brusca; nesse sentido, alerta KANT, que isso, pois, poderia ocasionar "a queda do despotismo pessoal ou da opressão ávida de lucros ou de domínios, porém nunca produzirá a verdadeira reforma do modo de pensar. Apenas novos preconceitos, assim como os velhos, servirão como cintas para conduzir a grande massa destituída de pensamento". ${ }^{16}$

Essa necessidade de se lutar contra a covardia e a preguiça na permanência da menoridade pela busca da maioridade representa em KANT, sem dúvida, no modo de exercício da liberdade, posto que para o esclarecimento nada mais se exige que a liberdade. Nesse sentido, a liberdade diz respeito ao uso público da razão, pois somente ela é capaz de levar o indivíduo ao seu estágio de esclarecimento. KANT, então, pergunta-se qual a limitação que impede o esclarecimento [Aufklärung], e por resposta

14 KANT, Immanuel. Beantwortung der frage..., p. 53. "Es ist so bequem, unmündig zu sein". [Trad. do autor]

15 KANT, Immanuel. Beantwortung der frage..., p. 58. "Ein Mensch kann zwar für seine Person, und auch alsdann nur auf einige Zeit, in dem, was ihm zu wissen obliegt, die Aufklärung aufschieben". [Trad. do autor]

16 KANT, Immanuel. Beantwortung der frage..., p. 54. “... ein Abfall von persönlichem Despotism und gewinnsüchtiger oder gerrschsüchtiger Bedrückung, aber niemals wahre Reform der Denkungsart zu Stande kommen; sondern neue Vorurteile werden, eben sowohl als die alten, zum Leitbande des gedankenlosen grossen Haufens dienen". [Trad. do autor] 
se lhe concede: o uso público da razão (aquele que qualquer homem, enquanto sábio, faz dela diante do grande público do mundo letrado) deve ser sempre livre e só ele pode realizar o esclarecimento; em contrapartida, o uso privado da razão (aquele que o sábio pode fazer de sua razão em um certo cargo público ou função a ele confiada), embora seja certamente limitado, também permite o progresso do esclarecimento.

Assim, o funcionário não só tem o direito, mas tem o dever de questionar a si próprio, a fim de expor as fraquezas da hierarquia em que trabalha, adquirindo, assim, sua independência; do mesmo modo, o militar, embora sirva, pode expor suas observações ao público para que as julguem; igualmente, ainda, o sacerdote, que deve ter completa liberdade para dar conhecimento ao público de todas as suas idéias, propostas para melhorar a instituição da religião e da igreja. O seu esclarecimento pressupõe a mudança lenta e gradativa que permite reconhecer as falhas e expô-las, isto é, fazendo o uso público e privado de sua razão para libertar-se dos erros institucionais e da menoridade em que se encontrava. Se no uso privado encontra-se preso à obediência, à razão nos seus limites, que também podem ser questionados, no uso público goza de liberdade ilimitada.

Nesse sentido, KANT afirma que os homens, no uso público e privado de suas razões, deixando de lado sua preguiça e sua coragem, devem deixar seu estado de minoridade, tornando-se autônomos para fazerem uso de seu próprio entendimento. Trata-se de um dever, e não de um destino que é dado ao indivíduo escolher se permanece na dependência de tutores ou não, é, antes, um dever com a humanidade: "Mas renunciar a ele (Aufklärung), significa ferir e calcar aos pés os sagrados direitos da humanidade". ${ }^{17}$ Nesse sentido, os indivíduos não podem de modo algum serem sujeitados ou impedidos de saírem de sua menoridade, nem mesmo um monarca pode fazê-lo, já que nem o indivíduo tem o direito de decidir se se esclarece ou não. A esta altura, KANT então se questiona: "Vivemos agora em uma época esclarecida?, a resposta será: não, vivemos em uma época de esclarecimento". ${ }^{18}$ Os homens só atingiriam efetivamente uma época esclarecida, se fossem capazes de, em conjunto, fazer uso seguro de seu próprio entendimento, sem serem dirigidos por outrem, especialmente em matéria religiosa (é o momento da laicização do Estado moderno). Todavia, embora se caminhasse para esse esclarecimento, reduzindo sensivelmente a cada dia os obstáculos, KANT alertava que os homens ainda não haviam conseguido tal feito, por suas próprias culpas, razão por que viviam em busca do rompimento da menoridade, é o século de FREDERICO.

Para encerrar, então afirma que os homens não só têm o dever de buscarem o esclarecimento, como têm a vocação ao "pensamento livre" [freien Denken], capaz de conduzi-los a um maior grau de liberdade, e, por consegüinte, ao esclarecimento, a

17 KANT, Immanuel. Beantwortung der frage..., p. 58. "Aber noch für die Nachkommenschaft, heibt die heiligen Rechte der Menschheit verletzen und mit Füssen treten". [Trad. do autor]

18 KANT, Immanuel. Beantwortung der frage..., p. 59. "Leben wir jetzt in einem aufgeklärten Zeitalter? So ist die Antwort: Nein, aber wohl in einem Zeitalter der Aufklärung". [Trad. do autor] 
partir do instante em que não são mais meros joguetes de tutores ou simples máquinas, eis suas derradeiras palavras: "Se, portanto, a natureza por baixo desse duro envoltório desenvolveu o germe de que cuida delicadamente, a saber, a tendência e a vocação ao pensamento livre, este atua em retorno progressivamente sobre o modo de sentir do povo (com o que este se torna capaz cada vez mais de agir de acordo com a liberdade), e finalmente, até mesmo sobre os princípios do governo, que acha conveniente para si próprio tratar o homem, que agora é mais do que simples máquina, de acordo com a sua dignidade". ${ }^{19}$

Feitas tais considerações, não há como deixar de visualizar que as próprias linhas kantianas, no seio do iluminismo, afirmam claramente a possibilidade, ou melhor dizendo, a necessidade que os homens têm de deixarem seu estado de necessidade e atingirem seu esclarecimento, tornando-se independentes de um tutor ou de outrem, podendo fazer o uso próprio do entendimento. Essa perspectiva kantiana demonstra que o próprio autor defende um uso "crítico" de seu tempo, o próprio iluminismo abre aqui espaço para pensar uma atitude crítica, tal como faz de outro modo FOUCAULT, sem que, com isso, anule-se o seu caráter iluminista. Pensar o contrário, engessando os próprios horizontes do iluminismo, significa nada menos do que, como visto neste crítico texto sobre a necessidade de afirmação da liberdade e do uso público da razão, deixar o próprio KANT fora da modernidade. ${ }^{20}$

De outro lado, essa interpretação do texto kantiano leva a um questionamento que FOUCAULT esboça, na defesa de seu projeto na linha neokantiana: a questão da atualidade. Para FOUCAULT, o que havia realmente de interessante no curto texto Was ist Aufklärung? era o fato de ser a primeira vez que um filósofo se propunha como tarefa filosófica a análise não somente dos sistemas ou dos fundamentos metafísicos do saber científico, mas, especialmente, pelo fato de se perguntar sobre um acontecimento histórico, algo de atualidade, tal como expressa em Pourquoi étudier le pouvoir: la question du sujet. ${ }^{21}$

Ademais, FOUCAULT afirma que KANT, ao se questionar sobre o que seria o esclarecimento, queria de fato se perguntar: "O que está acontecendo neste momento?

19 KANT, Immanuel. Beantwortung der frage..., p. 61. "Wenn denn die Natur unter dieser harten Hülle den Keim, für den sie am zärtlichsten sorgt, nämlich den Hang und Beruf zum freien Denken, ausgewichkelt hat: so wirkt dieser allmählich zurück auf die Sinnesart des Volks (wordurch dieses der Freiheit zu handeln nach und nach fähiger wird), und endlich auch sogar auf die Grundsätze der Regierung, die es ihr selbst zuträglich findet, den Menschen, der nun mehr als Machine ist, seiner Würde gemäb zu behandeln". [Trad. do autor]

20 Sobre as considerações kantianas da Aufklärung, convém ler: TERNES, José. Analítica da finitude: Kant, Heidegger, Foucault. Revista FilosojoV, Goiás, Ed. da UFG, v. 3, n. 2, p. 47-59, jul./dez. 1998; e KÖGLER, Hans-Herbert. Fröhliche subjektivität: historische ethik und dreifache ontologie beim späten Foucault. Ethos der Moderne: Foucaults Kritik der Aufklärung. Eva Erdmann, Rainer Forst e Axel Honneth (orgs.). Frankfurt: Campus Verlag, 1990, p. 202-228; e ROUANET, Sérgio Paulo. As razões do iluminismo. São Paulo: Companhia das Letras, 1987, p. 222-228.

21 FOUCAULT, Michel. Pourquoi étudier le pouvoir: la question du sujet. DREYFUS, Hubert; RABINOW, Paul. Michel Foucault: un parcours philosophique, au-delà de l'objectivité et de la subjetivité. Trad. Fabienne Durand-Bogaert. Paris: Gallimard, 1984, p. 307. 
O que está chegando até nós? Qual é este mundo, este período, este momento preciso em que vivemos? Quem somos nós? Quem somos enquanto Aufklärer [esclarecedores], enquanto testemunhas deste século das Luzes?".22 FOUCAULT entendia que a questão da atualidade estava intimamente presente nas considerações kantianas. Nesse sentido, FOUCAULT destaca que a pergunta kantiana é justamente oposta à concepção cartesiana de: quem sou eu?, como sujeito único, universal e não histórico, isto é, para DESCARTES não importava em que período, nem onde, nem todos, mas simplesmente o sujeito racional.

FOUCAULT se mostra claramente kantiano quando afirma no referido texto sobre o porquê em se estudar o poder para estudar o sujeito, que a tarefa filosófica deveria ser aquela que se pergunta sobre o "somos" nesse preciso momento, não pelo que se descobre dos homens, mas pelo que se recusa em si próprio. ${ }^{23}$ É a necessidade de se impor o próprio presente como objeto da atitude crítica, que sua relação com KANT se estabelece no âmbito da ontologia. A modernidade está, dessa maneira, ainda mais viva nos questionamentos que FOUCAULT se lhe impõe na historicidade das práticas de subjetivação que ele utiliza em seu método arqueogenealógico. ${ }^{24}$ Nesse sentido, igualmente ressalta o professor da Universidade de Paris XII, FRÉDÉRIC GROS: "o que se descobre nos anos oitenta é um FOUCAULT reivindicando sua inscrição numa tradição 'moderna', aberta por KANT, um FOUCAULT que tenta dar à filosofia a dimensão de uma tarefa histórico-crítica". ${ }^{25}$ A par das considerações do ilustre professor GROS, que pela passagem indica somente ver um FOUCAULT kantiano a partir de sua viragem ética, é oportuno verificar que o FOUCAULT de Surveiller et Punir, bem como o ambivalente em Les Mots et les Choses, também já se constituíra na linha direta da modernidade kantiana. Dessa maneira, toda a obra foucaultiana se inscreve na modernidade, não epistêmica, mas ontológica. Nesse sentido, segundo GUILLAUME LE BLANC, num artigo intitulado Le Conflit des Modernités Selon Foucault, publicado na Revista Magazine Littéraire em abril de 1993, para FOUCAULT, KANT estaria situado em sua obra no cruzamento de duas figuras da modernidade: uma epistêmica, que ele procura incansavelmente negar; e, outra, ontológica, que ele valoriza na sua ontologia crítica. ${ }^{26}$

22 FOUCAULT, Michel. Pourquoi étudier le pouvoir..., p. 307. "Qu'est-ce qui se passe en ce moment? Qu'est-ce qui nous arrive? Quel est ce monde, cette période, ce moment précis où nous vivons? Qui sommes-nous? Qui sommes-nous en tant qu'Aufklärer, en tant que témoins de ce siècle des Lumières?". [Trad. do autor]

23 FOUCAULT, Michel. Pourquoi étudier le pouvoir..., p. 308.

24 Nesse ponto, sem dúvida, FOUCAULT se aproxima de KANT, ao conceber a necessidade do duplo empírico-transcendental como condição de possibilidade do conhecimento. Para tanto, convém ver as verticais observações em HAN, Béatrice. L'ontologie manquée de Michel Foucault..., p. 72.

25 GROS, Frédéric. Foucault et le projet critique. Revue Raison Presénte. Paris, Centre National du Livre, n. 114, p. 03, avr./jun. 1995. "Ce qui se découvre dans les années quatre-vingt, c'est un Foucault revendiquant son inscription dans une tradition 'moderne' ouverte par Kant, un Foucault qui tente de donner à la philosophie la dimension d'une tâche historico-critique". [Trad. do autor]

26 LE BLANC, Guillaume. Le conflit des modernités selon Foucault. Magazine Littéraire, Paris, n. 09, p. 56-60, avril 1993. 
A exposição foucaultiana sobre o tema do esclarecimento, que permite aproximálo quanto a essa perspectiva ontológica crítica de KANT, mas que ao mesmo tempo permite distanciá-lo do autor alemão, a razão moderna, é fartamente tratada por FOUCAULT em Qu'est-ce que les lumières?, no curso proferido por FOUCAULT em 5 de janeiro de 1983 no Collège de France, e no artigo não revisado Qu'est-ce que la critique? Critique et Aufklärung, publicado no Bulletin de la Société Française de Philosophie, entre abril e junho de 1990. No primeiro texto, a temática kantiana aparece na interpretação que FOUCAULT faz desse artigo, a fim de demonstrar a passagem da crítica à antropologia. Embora para FOUCAULT parecesse um texto menor, seria indispensável para explicar uma temática que até hoje traria diversos questionamentos, especialmente ao propor a definição do que seria Aufklärung.

A importância, como visto, reside no fato de se questionar sobre o "presente", todavia, alerta FOUCAULT que não teria sido a primeira vez que isso havia sido feito, ao menos sob outras três formas já o teriam: i) já havia buscado se representar o presente como inerente a uma certa idade do mundo, dotado de características; ii) interrogar o presente para tentar encontrar nele os signos anunciadores de um acontecimento futuro; iii) analisar o presente como um ponto de transição em direção à aurora de um novo mundo. Entretanto, o pensador francês entende que o feito de KANT era totalmente distinto dos questionamentos até então feitos nessas linhas. Seu objetivo era definir o Aufklärung não a partir de uma totalidade ou de um acontecimento futuro, mas de maneira quase inteiramente negativa, como uma saída, uma partida, que o caracteriza como um processo capaz de livrar o homem de seu estado de minoridade. ${ }^{27} \mathrm{O}$ entendimento de minoridade residiria, segundo sua interpretação, em "um certo estado de nossa vontade que nos faz aceitar a autoridade de qualquer um para nos conduzir nos domínios onde convém fazer uso da razão". ${ }^{28}$ Segundo FOUCAULT, estariam presentes nesse texto algumas considerações indispensáveis: a imbricação preexistente entre vontade, autoridade, e uso da razão; a Aufklärung como um fato, um processo, mas também uma obrigação que representaria uma mudança que o próprio homem deveria operar em si mesmo. Nesse sentido, destaca que a Aufklärung, atingida pela coragem e pela audácia de saber, seria tanto um processo individual, quanto um processo coletivo.

De outro lado, FOUCAULT defende, no percurso em busca do esclarecimento, que KANT teria definido duas condições essenciais para que o homem saísse de sua minoridade, condições essas espritiruais e institucionais, éticas e políticas. A primeira seria aquela que permite distinguir o que se destaca na obediência e o que se destaca no uso da razão, e que KANT o faz a partir da diferenciação entre o uso público, que deve ser livre, e o uso privado da razão, que, por sua vez, deve ser submisso, contrariamente à liberdade de consciência. Consoante FOUCAULT, KANT entendia que o homem

27 FOUCAULT, Michel. Qu'est-ce que les lumières?..., p. 64.

28 FOUCAULT, Michel. Qu'est-ce que les lumières?..., p. 64. “... un certain état de notre volonté qui nous fait accepter l'autorité de quelqu'un d'autre pour nous conduire dans les domaines où il convient de faire usage de la raison". [Trad. do autor] 
fazia um uso privado da razão, sempre que se tornasse uma peça de funcionamento da sociedade, como: ser um soldado, pagar impostos, ser sacerdote etc. (o importante seria que os homens obedecessem, segundo um uso adaptado às circunstâncias); em contrapartida, fazer um uso público da razão seria, como condição para o esclarecimento, fazer um uso universal, um uso livre do entendimento.

Entretanto, FOUCAULT se pergunta: como assegurar um uso público da razão? O esclarecimento não deve ser alcançado simplesmente como um processo geral afeto de toda a humanidade, ou como uma obrigação prescrita aos indivíduos, mas como um problema político, por isso, o questionamento se impõe da seguinte maneira: como o uso da razão pode ter a forma pública que lhe é necessária?; como a audácia de saber pode se exercer em pleno dia, enquanto que os indivíduos estão a obedecer? ${ }^{29}$ Nesse sentido, entende FOUCAULT que KANT, ao resgatar FREDERICO II, estabelece que o uso público e livre da razão autônoma seria a melhor garantia de obediência. Dessa maneira, a Aufklärung se define como o momento em que a humanidade fará uso de sua própria razão, sem se submeter a nenhuma autoridade, isto é, o momento que em o uso da razão é légitmo para valorizar a Crítica, para determinar: o que se pode conhecer, o que é necessário fazer, e o que é permitido esperar.

É nessa linha que FOUCAULT entende que esse breve texto kantiano se impõe como uma reflexão sobre o que seria a modernidade em si. Para o autor, antes de ser simplesmente um período histórico, precedido da pré-modernidade, inocente e arcaica, e procedida da pós-modernidade, enigmática e inquieta, seria uma atitude, essencialmente crítica, posto que seria antes de que um processo histórico uma maneira de pensar e de sentir, de agir e de se conduzir, um ethos, enfim, uma maneira de pensar o presente. Nesse sentido, o texto kantiano se inscreve como uma tarefa filosófica sobre a atualidade, e faz rescender uma "atitude de modernidade". Essa atitude se demonstraria, sobretudo, no texto de BAUDELAIRE, e sua definição como um sentimento de ruptura e novidade, ao mesmo tempo que de transitoriedade, de fugacidade e contingência, seguindo ao lema: "Você não tem o direito de desprezar o presente!". ${ }^{30}$ Nesse sentido, a modernidade baudelariana, para FOUCAULT, seria um exercício em que a extrema atenção ao real seria confrontada a uma prática de liberdade, que respeita, ao mesmo tempo, o real e a sua violação; algo que lhe garantisse a característica de voluntariedade, um ascetismo indispensável.

Entretanto, FOUCAULT alerta que o seu propósito não é nem resumir o acontecimento histórico que foi a Aufklärung, nem tampouco dissecar as diferentes formas da atitude da modernidade, mas tão-somente inserir a Aufklärung como um tipo de interrogação filosófica capaz de problematizar a relação entre o presente, o modo de ser histórico e a constituição de si mesmo como sujeito autônomo; como uma espécie de reativação permanente de uma atitude, de um ethos filosófico. Para caracterizar esse 
ehtos como crítica permanente do ser histórico, FOUCAULT o faz essencialmente sob duas maneiras: uma negativa, e outra positiva.

Negativamente, FOUCAULT defende que esse ethos no texto kantiano, ao representar, enfim, o ethos da modernidade filosófica, deveria ser representado como um modo de filosofar, não ser nem a favor nem contra a Aufklärung, mas antes uma maneira de recusar tudo o que se apresenta sob a forma de uma alternativa simplista e autoritária, em que se deve aceitar o esclarecimento como modo de continuar no racionalismo ou recusá-lo, criticando-o e buscando escapar aos seus princípios racionais, aquilo que FOUCAULT chama de "chantagem". "Esse ethos implica, inicialmente, que se recusa o que eu chamarei de 'chantagem' da Aufklärung. Eu acredito que a Aufklärung como um conjunto de acontecimentos ${ }^{31}$ políticos, econômicos, sociais, institucionais, culturais, dos quais nós dependemos ainda, para uma grande parte constitui um domínio de análise privilegiada". ${ }^{2}$ Entretanto, alerta FOUCAULT que a Aufklärung não se trata de um humanismo, posto que é um acontecimento ou um conjunto de acontecimentos e processos históricos complexos, situados num determinado desenvolvimento da sociedade européia, contendo elementos de transformações sociais, das instituições políticas, das formas de saber, dos projetos de racionalização etc. É, pois, uma forma de reflexão filosófica referente ao presente; em contrapartida, o humanismo é um conjunto de temas que reaparecem no tempo constantemente nas sociedades européias, ligados aos julgamentos variados de valor, ora como críticos do cristianismo, ora como críticos do ascetismo, ora como crítico do teocentrismo etc. Há várias formas de humanismo na história: marxismo, existencialismo, personalismo... Todavia, todos são incapazes de se compreender como uma "atitude crítica".

De outro lado, positivamente, FOUCAULT defende que a Aufklärung, enquanto um ethos filosófico, teria um sentido positivo a partir do instante em que ele se colocar como uma crítica do que se diz, do que se pensa e se faz, por meio de uma ontologia histórica do próprio homem. Trata-se de uma "atitude-limite": "Não se trata de um comportamento de recusa. Deve-se escapar à alternativa do exterior e do interior; é necessário estar na fronteira. A crítica é precisamente a análise dos limites e a sua reflexão. Mas se a questão kantiana era de saber quais limites o conhecimento deveria renunciar a transpor, parece-me que a questão crítica de hoje deve ser revista como questão positiva: nisto que nos é dado como universal, necessário, obrigatório, qual é a parte desse que é singular, contingente e sujeito a coações arbitrárias. Trata-se, em suma, de transformar a crítica exercida na forma de limitação necessária numa crítica

31 Sobre a noção de acontecimento em FOUCAULT, é indispensável a leitura da Professora de Sociologia da USP IRENE CARDOSO, que repensa o acontecimento como uma problematização que permite o questionamento sobre a atualidade. Ver: CARDOSO, Irene de Arruda Ribeiro. Foucault e a noção de acontecimento. Revista de Sociologia Tempo Social. São Paulo: Edusp, ano 7, n. 1-2, p. 53-66, out. 1995.

32 FOUCAULT, Michel. Qu'est-ce que les lumières? ..., p. 69. "Cet ethos implique d'abord qu'on refuse ce que j'appellerai volontiers le 'chantage' à l'Aufklärung. Je pense que l'Aufklärung comme ensemble d'événements politiques, économiques, sociaux, institutionnels, culturels dont nous dépendons encore pour une grande partie constitue un domaine d'analyse privilégiée". [Trad. do autor] 
prática na forma da transposição possível". ${ }^{33}$ Essa crítica, segundo FOUCAULT, não é transcendental nem tampouco metafísica, mas genealógica na sua finalidade e arqueológica em seu método. E, nesse sentido, a crítica genealógica "não deduzirá da forma do que somos o que nos é impossível de fazer ou de conhecer; mas ela se desenvolverá da contingência que nos fez ser o que nós somos, a possiblidade de não ser, fazer ou pensar o que somos, fazemos ou pensamos". ${ }^{34}$

Para FOUCAULT, essa atitude filosófica, liberta do pensamento kantiano, deve ser, no que couber, uma atitude experimental, isto é, "no que couber" significa dizer que há um conteúdo essencialmente crítico, que interroga os limites do próprio homem, mas também há todo um outro domínio, que se refere à realidade, à atualidade. Nesse sentido, a atitude crítica deve se distanciar de qualquer projeto que deseja se inscrever como global e radical, e se aproximar do projeto que se situe no limbo entre a atitude histórica e a atitude prática, isto é, que seja capaz de examinar vários campos de domínio de saber (o saber aqui deve ser visto tal a definição referida por FOUCAULT, como o conjunto de procedimentos e efeitos que um campo específico está disposto a aceitar em um determinado momento), ${ }^{35}$ como os modos de ser e de pensar, as relações de autoridade, entre os sexos, entre a normalidade e a loucura, entre a disciplina e a prisão etc. Esse é, para FOUCAULT, portanto, o ethos filosófico próprio da "ontologia crítica" do próprio homem como uma prova histórico-prática dos limites a se transpor: "como trabalho de nós-mesmos sobre nós-mesmos enquanto somos seres livres". ${ }^{36}$

Essa "atitude da modernidade", por ser um ethos filosófico cujo legado kantiano impõe ao presente, no repensar da atualidade, reveste-se de quatro características ou domínios essenciais: de um lado, a idéia de cena, de jogo, a partir do instante que coloca lado a lado a capacidade técnica e a liberdade dos indivíduos, quer dizer, ao cruzamento das capacidades e o cruzamento da autonomia, que leva à seguinte pergunta: "Como desconectar o cruzamento das capacidades e a intensificação das relações de poder?"; 37 de outro lado, a homogeneidade, que se refere ao que os homens fazem do

33 FOUCAULT, Michel. Qu'est-ce que les lumières?..., p. 70. "Il ne s'agit pas d'un comportement de rejet. On dois échapper à l'alternative du dehors et du dedans; il faut être aux frontières. La critique, c'est bien l'analyse des limites et la réflexion sur elles. Mais si la question kantienne était de savoir quelles limites la connaissance doit renoncer à franchir, il me semble que la question critique aujourd'hui doit être retournée en question positive: dans ce qui nous est donné comme universel, nécessaire, obligatoire, quelle est la part de ce qui est singulier, contingent et dù à des contraintes arbitraires. Il s'agit en somme de tranformer la critique exercée dans la forme de la limitations nécessaire en une critique pratique dans la forme du franchissement possible". [Trad. do autor]

34 FOUCAULT, Michel. Qu'est-ce que les lumières?..., p. 71. "... elle ne déduira pas de la forme de ce que nous sommes ce que'il nous est impossible de faire ou de connaître; mais elle dégagera de la contingence qui nous a fait être ce que nous sommes, la possibilité de ne plus être, faire ou penser ce que nous sommes, faisons ou pensons". [Trad. do autor]

35 FOUCAULT, Michel. Qu'est-ce que la critique?..., p. 57. [Trad. br. O que é a crítica? ..., p. 183]

36 FOUCAULT, Michel. Qu'est-ce que les lumières?..., p. 72. “... comme travail de nous-mêmes sur nous-mêmes en tant qu'être libres'. [Trad. do autor]

37 FOUCAULT, Michel. Qu'est-ce que les lumières?..., p. 72. "Comment déconnecter la croissance des capacités et l'intensification des relations de pouvoir?". [Trad. do autor] 
que eles fazem, isto é, as formas de racionalidade que organizam as maneiras de se fazer; a sistematicidade, cujo conjunto de práticas é capaz de destacar as relações de domínio sobre as coisas, as relações de ação sobre os outros, e as relações sobre si mesmo; e, por fim, a generalidade, pelo fato de se debruçarem sempre sobre um material, uma época, um conjunto de práticas e de discursos determinados.

Na releitura do texto kantiano, que leva certamente à possibilidade de defesa de um FOUCAULT moderno, tal como se propusera no início, o intelectual francês se questiona sobre o fato do homem atual não ser "maior", no sentido da Mündigkeit, e que o acontecimento da Aufklärung certamente não foi capaz de levar o homem a esse estágio ainda, mas seria indispensável colocar essa questão no presente, pois a Aufklärung seria uma maneira de filosofar. Esse ethos filosófico, essa ontologia crítica do próprio homem não é uma teoria, uma doutrina ou um corpus permanente de saber, mas uma "atitude", em que a crítica se traduz de diversas formas, especialmente na linha entre arqueologia e genealogia, na compreensão da coerência entre as práticas concretas, as tecnologias de racionalidade e os jogos estratégicos de liberdade.

Anos mais tarde, a presença das reflexões kantianas em FOUCAULT se tornam evidentes. Num artigo intitulado Qu'est-ce la Critique? Critique et Aufklärung FOUCAULT volta a se perguntar sobre a "atitude da modernidade", mas sob outro enfoque, então direcionado numa perspectiva histórica, quando se propõe brevemente fazer uma arqueologia da atitude crítica, e numa pespectiva política, quando se impõe uma investigação genealógica dos conjuntos de práticas. Para o intelectual francês, ao fazer uma arqueologia da atitude crítica, entende que esta teria seus horizontes limiares na pastoral cristã ou a igreja cristã, isto é, como atitude de recusa dos magistérios eclesiásticos, do retorno à Escritura, mas que sua reformulação, num espaço e de atualidade teria sido com a questão da Aufklärung retomada por KANT. De outro lado, FOUCAULT relaciona a "atitude crítica" com a governamentalização, isto é, para o autor, a questão da Aufklärung vem buscar respostas ao questionamento contínuo: "Como não ser governado?". ${ }^{38}$ A atitude crítica, como a arte de não ser excessivamente governado, situa-se no problema da autoridade, como movimento através do qual o sujeito reconhece o direito de interrogar a verdade nos seus efeitos de poder e discursos de verdade, implica, portanto, no des-sujeitamento. Nesse sentido kantiano, para FOUCAULT a atitude crítica representa o modo pelo qual a humanidade pode fugir de qualquer direção, fugir ao excesso de autoridade. Nesse sentido, a Aufklärung, nas particularidades das experiências que teve, especialmente na França e na Alemanha, como ontologia do presente se difere da crítica anteriormente realizada, pois a ela não interessa saber os limites do conhecimento, ou seja, a linha divisória da legitimidade como determinação do momento do erro ou da ilusão, mas as relações que podem ser estabelecidas e assinaladas entre os mecanismos de coerção e os elementos de conhecimento, em suma, a relação entre saber e poder, este visto como mecanismos particulares, definíveis e indefinidos na determinação ou nos discursos.

Para FOUCAULT, a atitude crítica, como ontologia do presente, é capaz de restituir ao acontecimento, ao conjunto histórico de práticas e discursos, uma 
positividade, que não deve ser analisado de maneira universal, mas nas suas particularidades, nas suas singularidades, como a loucura no mundo moderno, a sexualidade ou o sistema jurídico-moral nos mecanismos penais. É preciso praticar uma événementialisation, uma "acontecimentalização", isto é, uma consciência do acontecimento, capaz de colocar em evidência as singularidades e as condições de aceitabilidade no jogo das interações e das estratégias múltiplas. Nessa relação entre saber e poder, neste tornar acontecimento e não querer ser governado, é que a atitude crítica, na distância da questão crítica, que vê a Aufklärung como um ethos, permite ver num FOUCAULT a modernidade presente. Eis o que aproxima FOUCAULT de uma ontologia kantiana do presente.

\section{REFERÊNCIAS BIBLIOGRÁFICAS}

ADORNO, Sérgio. Dor e sofrimento: presenças ou ausências na obra de Foucault? In: Cadernos da Faculdade de Filosofia e Ciência de Marília. "Michel Foucault: histórias e destinos de um pensamento". Fávia Biroli e Marcos César Alvarez (orgs.). Marília: Unesp, v. 9, n. 1, p. 11-33, 2000 .

CARDOSO, Irene de Arruda Ribeiro. Foucault e a noção de acontecimento. Revista de Sociologia Tempo Social. São Paulo: Edusp, ano 7, n. 1-2, out. 1995, p. 53-66.

ERIBON, Didier. Michel Foucault. Trad. de Hildegard Feist. São Paulo: Companhia das Letras, 1990. $351 \mathrm{p}$.

FOUCAULT, Michel. Pour une morale de l'inconfort. Dits et Écrits. Daniel Defert et François Ewald (orgs.). Paris: Gallimard, v. 3, 1994, p. 783-787.

Pourquoi étudier le pouvoir: la question du sujet. DREYFUS, Hubert; RABINOW, Paul. Michel Foucault: un parcours philosophique, au-delà de l'objectivité et de la subjetivité. Trad. de Fabienne Durand-Bogaert. Paris: Gallimard, 1984, 364 p. Trad. ing. Why study power? The question of the subject. Trad. de Leslie Sawyer. Critical Inquiry, Chicago, v. 08, n. 04, summer, 1982, p. 777-796.

. Qu'est-ce que la critique? Critique et Aufklärung. Bulletin de la Société Française de Philosophie. Paris, abr.jun. 1990, n. 2, p. 35-63. Trad. br. O que é a crítica? Crítica e Aufklärung. Trad. Antônio C. Galdino. Cadernos da Faculdade de Filosofia e Ciência de Marília "Michel Foucault: histórias e destinos de um pensamento". Fávia Biroli e Marcos César Alvarez (orgs.). Marília: Unesp, v. 9, n. 1, 2000, p. 169-189.

Qu'est-ce que les lumières? Magazine Littéraire. Paris, n. 09, avril, p. 61-73, 1993. Trad. al. Was ist aufklärung? Ethos der Moderne: Foucaults Kritik der Aufklärung. Eva Erdmann, Rainer Forst e Axel Honneth (orgs.). Frankfurt: Campus Verlag, 1990, p. 35-54.

Une histoire restée muette. Dits et Écrits. Daniel Defert et François Ewald (orgs.). Paris: Gallimard, v. 1, 1994, p. 545-549.

GROS, Frédéric. Foucault et le projet critique. Revue Raison Presénte. Paris, Centre National du Livre, n. 114, avr./jun. 1995, p. 03-22.

Foucault e a questão do quem somos nós? In: Revista de Sociologia da USP Tempo Social, São Paulo, v. 7, n. 1-2, out. 1995, p. 175-178.

HABERMAS, Jürgen. La modernité: un projet inachevé. Critique: Revue générale des publications françaises et étrangère. Paris, n. 413, oct. 1981, p. 950-967. 
. Une flèche dans le coeur du temps présent. Critique: Revue générale des publications françaises et étrangère. Paris, n. 471-472, août/septembre, 1986, p. 794-799.

HAN, Béatrice. L'ontologie manquée de Michel Foucault: entre l'historique et le transcendantal. Grenoble: Millon, 1998. 325 p.

KANT, Immanuel. Beantwortung der frage: was ist aufklärung? Schriften zur anthropologie geschichtsphilosophie, politik und pädagogik 1. Frankfurt: Suhrkamp, 1991, p. 53-61.

KÖGLER, Hans-Herbert. Fröhliche subjektivität: historische ethik und dreifache ontologie beim späten Foucault. Ethos der Moderne: Foucaults Kritik der Aufklärung. Eva Erdmann, Rainer Forst e Axel Honneth (orgs.). Frankfurt: Campus Verlag, 1990, p. 202-228.

LE BLANC, Guillaume. Le conflit des modernités selon Foucault. Magazine Littéraire. Paris, n. 09, avril 1993, p. 56-60.

MERQUIOR, José Guilherme. Michel Foucault ou o niilismo de cátedra. Trad. Donaldson M. Garschagen. Rio de Janeiro: Nova Fronteira, 1985. 277 p.

ROUANET, Sérgio Paulo. As razões do iluminismo. São Paulo: Companhia das Letras, 1987. $349 \mathrm{p}$.

SANTOS, Boaventura de Souza. A crítica da razão indolente: contra o desperdício da experiência. São Paulo: Cortez, 2000. 415 p.

TERNES, José. Analítica da finitude: Kant, Heidegger, Foucault. Revista FilosojoV, Goiás, Ed. da UFG, v. 3, n. 2, jul./dez. 1998, p. 47-59. 